\title{
EQUIVALENT INTEGRAL CONDITIONS RELATED TO BILINEAR HARDY-TYPE INEQUALITIES
}

\section{Saikat Kanjilal, Lars-Erik Persson and Guldarya E. Shambilova}

Abstract. Infinitely many, even scales of, equivalent conditions are derived to characterize the bilinear Hardy-type inequality under various ranges of parameters.

Mathematics subject classification (2010): 26D10, 46E35.

Keywords and phrases: Inequalities, the Hardy inequality, bilinear Hardy-type inequalities, scales of equivalent conditions.

\section{REFERENCES}

[1] A. Gogatishvili, A. Kufner, L.-E. Persson And A. Wedestig, An equivalence theorem for integral conditions related to Hardy's inequality, Real Analysis Exchange, 29, 2 (2003), 1-14.

[2] M. KRePela, Iterating bilinear Hardy inequalities, Proc. Edinb. Math. Soc. 60, 4 (2017), 955-971.

[3] A. Kufner, L.-E. Perss on AND N. SAmKo, Weighted Inequalities of Hardy Type, Second Edition, World Scientific New Jersey, 2017.

[4] L.-E. PERSSON AND V. D. STEPANOV, Weighted integral inequalities with the geometric mean operator, J. Inequal. Appl. 7, (2002), 727-746.

[5] L.-E. Persson, V. D. StePanov And P. WALl, Some scales of equivalent weight characterizations of Hardy's inequality: the case $q<p$, Math. Inequal. Appl. 10, 2 (2007), 267-279.

[6] A. Wedestig, Weighted Inequalities of Hardy Type and their Limiting Inequalities, Doctoral Thesis, Department of Mathematics, Luleå, University of Technology, Sweden, 2003.

[7] E. P. Ushakova, Norm Inequalities of Hardy and Pólya-Knopp Types, Doctoral Thesis, Department of Mathematics, Luleå, University of Technology, Sweden, 2006.

[8] G. E. Shambilova, Some New Hardy-Type Inequalities on the Cone of Monotone Functions, Doctoral Thesis, Department of Mathematics, Luleå, University of Technology, Sweden, 2018. 